manual include: Establishing Safety policies and Procedures; Identifying and assessing Hazards and Risks; Preventing and Controlling Hazards and Risks; Educating and Training Employees; and Evaluating Training Program and Resources. The manual provides several examples and forms that help users adapt and implement a safety and health management plan that matches their operation. The safety and health management plan also helps farm and ranch owners be aware of safety and health regulations that their operation may be under.

Conclusions The Safety and Health Management Planning for General Farm and Ranch Operations has been well accepted by the agricultural community. The manual is in its second printing and has been used as part of an Agricultural Safety and Health Certificate course for safety professionals and insurers loss control specialist offered by the International Society of Agricultural Safety and health. It is also serving as a basis to develop companion manuals for specific types of farming operations such as biomass producers and dairy producers.

\section{INJURY SURVEILLANCE IN A DECENTRALISED U.S. SYSTEM: INNOVATIVE APPROACH TO FIND NEW HAZARDS, 2015}

${ }^{1}$ Stephen C Waring, ${ }^{2}$ Kathrine Barnes, ${ }^{3}$ Jeffrey VanWormer, ${ }^{2}$ Matthew C Keifer. ${ }^{1}$ Essentia Institute of Rural Health; ${ }^{2}$ National Farm Medicine Centre, Marshfield Clinic Research Foundation, USA; ${ }^{3}$ Center for Clinical Epidemiology and Public Health, Marshfield Clinic Research Foundation, USA

\subsection{6/injuryprev-2016-042156.146}

Background Identifying emergent themes in safety begins with data that illustrate changes in rates of injury and illness. Oftentimes, these data are borne from surveillance systems. Dairy farming is a useful case study, as it is among the most hazardous domestic jobs and increasingly technology-driven. Thus, surveillance of injury and illness on dairy farms is a chore ripe with challenge as well as necessity. Located in the second largest dairy producing state and with electronic health records covering over $90 \%$ of the healthcare service population, the study provides a valuable example in surveillance.

Description of the problem The agricultural and healthcare industries in the U.S. are as decentralised and fragmented as the data sources that track them. Prior and current agricultural injury surveillance systems suffer from a dearth of data and difficulty determining farm exposures from existing resources. Response rates on injury surveys tend to be low, thus combining data from different sources and with different operationalizations is necessary but provides an additional problem to effective surveillance.

Results A surveillance program is built by first leveraging the grounded knowledge of agriculturalists. Relationship-building is imperative in accessing the best data available and appropriately linking disparate data sets. Dairy license information, farm vehicle registrations, and federal farm subsidy recipients are used to enumerate a sample of dairy farmers. This information is then linked to electronic health records, health payer claims, and mail surveys in order to cull injury and illness events, as well as current safety practices. Rates of injury and illness are examined at regular intervals.

Conclusions The current project may serve as a model for creatively overcoming the unique challenges of passive, ongoing surveillance in a decentralised system, with broader implication for public health safety surveillance programs in other world regions.

\section{EFFECTIVENESS OF OPERATOR PROTECTION DEVICES TO MITIGATE INJURIES ASSOCIATED WITH QUAD-BIKE (ATV) ROLLOVERS}

'David Hicks, ${ }^{1}$ Raphael Grzebieta, ${ }^{1}$ Soufiane Boufous, ${ }^{1}$ George Rechnitzer, ${ }^{2}$ David Robertson, ${ }^{1}$ Keith Simmons. 'Transport and Road Safety(TARS), University of New South Wales, Australia; ${ }^{2}$ Quadbar Industries, Australia

\subsection{6/injuryprev-2016-042156.147}

Background There is growing concern regarding the number of serious injuries and fatalities related to quad bikes (All-Terrain Vehicle or ATV) in many countries of the world related to the farming sector. There have been over 150 quad bike fatalities in Australia since 2000, many of which involve the rider losing control at a low speed with the vehicle subsequently rolling on top of the rider and crushing or asphyxiating them. Operator Protection Devices (OPDs) developed in Australia and New Zealand are designed to reduce the potential of such incidents. Manufacturers, however, claim that OPDs have the potential to increase the incidence of injuries and deaths during a rollover event. Currently, there are around 3000 OPDs fitted to quad bikes in Australia and are now being sold in the USA.

Methods 300 farmers and other users who have a Quadbar OPD fitted to their quad bike will be surveyed about the performance of the quadbar in a rollover event. Participants will be asked about their quad bike usage patterns and history of rollover events before and after the fitment of a Quadbar. Participants will be interviewed face to face and via telephone.

Results Information on rider demographics, usage for work (mustering, carrying loads, transporting, etc.) and other purposes (recreational), terrain over which the quad bikes are ridden, direct information relating to incidents involving quad bikes with and without an OPD, injuries resulting from an OPD, and other safety relevant information, will be collected.

Conclusions The study will provide real world recorded evidence determining whether indeed the injury risk when using an OPD on a quad bike (ATV) increases or instead reduces crush related injury and asphyxia fatality potential and related to purpose of task.

\section{ROAD ACCIDENTS AS AN OCCUPATIONAL SAFETY PROBLEM}

${ }^{1}$ Tarja Ojala, ${ }^{2}$ Marja Kaari, ${ }^{2}$ Mika Tynkkynen, ${ }^{3}$ Kalle Parkkari. ${ }^{1}$ Safety Futures Ky, Finland; 'Finnish Workers' Compensation Centre (TVK), Finland; ${ }^{3}$ The Finnish Motor Insurers' Centre, Finland

\subsection{6/injuryprev-2016-042156.148}

Background Finland currently uses two parallel preventive accident investigation systems. Fatal accidents occurring at work are investigated as occupational accidents. Fatal accidents occurring in traffic are investigated as road accidents.

In professional driving, fatal road accidents are road and occupational accidents at the same time, but the accident investigation method used is the same as in road accidents. However, the 